\title{
PERANAN PENYULUH PERTANIAN LAPANG (PPL) DALAM ADOPSI PENGELOLAAN TANAMAN TERPADU (PTT) USAHATANI PADI SAWAH DI KECAMATAN SEPUTIH RAMAN
}

\author{
(The Role of Agricultural Extension Workers on Adoption of Integrated Crop Management \\ of Rice Paddy Farming)
}

Rendi Henda Ramadhan, Begem Viantimala, Serly Silviyanti

Jurusan Agribisnis, Fakultas Pertanian,Universitas Lampung, Jl. Prof. Dr. Soemantri Brodjonegoro No.1 Bandar Lampung 35145, Telp. 082281502828, e-mail: Rendi255863@gmail.com

\begin{abstract}
This study aims to determine the level of role of agricultural extension workers on adopting integrated crop management, determine the level of adoption of integrated crop management of paddy rice in increasing productivity, analyze the relationship between the role of agricultural extension workers and adoption of integrated crop management, and analyze the relationship between adoption of integrated crop management and the productivity of lowland rice. Determination of sampling conducted by proporsional random sampling and obtained 99 people divided into eight agricultural extension work areas. The research data is analyzed by descriptive and inferential statistics of Rank Spearman correlation test. The results of the study showed that the role of field agricultural extension workers in the management of integrated crops of paddy fields was in the medium classification; these roles included activities in education, dissemination, facilitation, consultation, supervision, monitoring, and evaluation. Adoption of integrated plant management based on the use of quality seeds and planting systems, irrigation, fertilization, control of plant pests, handling of harvests to post-harvest were in the medium classification. The role of field agricultural extension workers was significantly correlated with the adoption of integrated crop management, while adoption of integrated crop management was related to the productivity of lowland rice.
\end{abstract}

Key words : adoption, agricultural extension workers, integrated crop management, paddy, roles

\section{PENDAHULUAN}

Sektor pertanian merupakan mata pencaharian sebagian besar masyarakat Indonesia. Pembangunan di sektor pertanian lebih mendapatkan perhatian dari pemerintah agar pertanian di Indonesia bisa menjadi sektor andalan yang dapat meningkatkan kesejahteraan petani. Salah satu komoditas utama yang ditanam petani Indonesia adalah padi yang menghasilkan beras sebagai makanan pokok penduduk Indonesia. Tingginya kebutuhan konsumsi beras disebabkan sebagian besar penduduk Indonesia beranggapan bahwa beras merupakan bahan makanan pokok yang belum dapat digantikan (Soetriono 2006). Tanaman pangan merupakan bagian penting yang tidak terpisahkan dari sektor pertanian. Khusus di Indonesia, tanaman pangan juga berkedudukan strategis dalam memelihara stabilitas ekonomi nasional. Oleh karena itu, subsektor tanaman pangan selalu mendapat perhatian lebih dari pemerintah. Perhatian tersebut dilakukan agar tujuan pembangunan pertanian di subsektor tanaman pangan tercapai yaitu program swasembada pangan di Indonesia.
Padi (oryza sativa) merupakan makanan pokok di Indonesia, oleh karena itu harus tersedia jumlah yang cukup banyak untuk memenuhi kebutuhan penduduk yang semakin meningkat di setiap tahunnya. Bagi sebagian besar petani, meningkatkan produksi padi merupakan hal yang penting untuk menyediakan bahan pangan terutama dalam pemenuhan kebutuhan keluarga, Provinsi Lampung sebagai salah satu lumbung padi di Indonesia menerapkan pendekatan Pengelolaan Tanaman Terpadu (PTT) dengan tujuan meningkatkan pengetahuan dan skill petani dalam budidaya padi, memberikan stimulan berupa bantuan benih dan bantuan pupuk. Provinsi Lampung merupakan salah satu daerah penghasil padi terbesar keenam di Indonesia yaitu sebesar 3.496.489 ton dengan produktivitas sebesar 5,14 ton/ha (Badan Pusat Statistik 2016).

Kabupaten Lampung Tengah merupakan penghasil padi sawah terbesar di Provinsi Lampung dan sebagai salah satu lumbung padi, dengan produksi sebesar 782.604 ton. Jumlah produksi yang dihasilkan berasal dari seluruh Kecamatan di Lampung Tengah. Kecamatan Seputih Raman pada tahun 2015 merupakan Kecamatan yang memiliki 
luas panen terluas dan produksi padi sawah terbesar di Kabupaten Lampung Tengah yaitu sebesar 89.167 ton dengan produktivitas 6.71 ton/ha. Berdasarkan potensi produksi dan produktivitas padi sawah yang dimiliki oleh Kecamatan Seputih Raman perlu adanya pendampingan dari PPL dalam memaksimalkan sumber daya yang telah ada dengan memberikan inovasi - inovasi tentang teknologi, serta meningkatkan produksi dan produktivitas yang dihasilkan.

Salah satu upaya dalam penigkatan produktivitas di Lampung Tengah, terutama di kecamatan Seputih Raman adalah dengan pendampingan dari PPL melalui peranannya untuk menimbulkan perubahan perilaku petani sesuai dengan yang dikehendaki dan diarahkan oleh tenaga penyuluh. Kegiatan penyuluhan pertanian mampu memberikan kontribusi yang nyata dalam meningkatkan produksi komoditi pertanian dan pendapatan petani (Effendi 2005).

Petani adalah subjek utama yang menentukan produktivitas usahatani yang dikelolanya. Secara naluri, petani menginginkan usahataninya memberikan manfaat tertinggi dari sumber daya yang dikelola. Produksi dan produktivitas dapat ditentukan dari sumber daya yang dimiliki petani dan tergantung pada cara yang diterapkan dalam usahataninya. Aspek pembangunan pertanian tidak terlepas dari kemampuan petani dalam mengadopsi dan menerapkan Pengelolaan Tanaman Terpadu (PTT) pada usaha taninya secara efektif. Hal ini membuktikan adanya peranan PPL dalam memberikan arahan dan masukan tentang pengelolaan lanjutan PTT padi sawah sehingga petani mau mengadopsi PTT tersebut dalam upaya peningkatan produktivitas padi sawah di Kecamatan Seputih Raman. Terkait dengan hal ini perlu dikaji penerapan peranan PPL dalam adopsi PTT.

Berdasarkan uraian sebelumnya, maka tujuan penelitian ini untuk mengetahui tingkat peranan PPL dalam adopsi PTT usahatani padi sawah di Kecamatan Seputih Raman, tingkat adopsi PTT usahatani padi sawah di Kecamatan Seputih Raman, menganalisis hubungan antara peranan penyuluh pertanian dengan adopsi PTT usahatani padi sawah di Kecamatan Seputih Raman, dan mengetahui hubungan antara adopsi PPT usahatani padi sawah dengan tingkat produktivitas padi di Kecamatan Seputih Raman.

\section{METODE PENELITIAN}

Metode yang digunakan dalam penelitian ini adalah metode survei yaitu penelitian yang mengambil sampel dari suatu populasi. Data yang digunakan dalam penelitian ini meliputi data primer dan data sekunder. Data primer diperoleh melalui hasil wawancara langsung. Data sekunder diperlukan sebagai tambahan informasi yang diperoleh dari literatur, dinas atau instansi terkait dan lembaga-lembaga yang berhubungan dengan penelitian ini. Lokasi penelitian adalah di Kecamatan Seputih Raman Kabupaten Lampung Tengah. Penentuan lokasi dilakukan secara sengaja (purposive) dengan pertimbangan bahwa produksi padi sawah di Kecamatan Seputih Raman adalah yang tertinggi diantara 28 Kecamatan lainnya yang terdapat di Kabupaten Lampung Tengah.

Analisis data yang digunakan untuk menjawab tujuan pertama dalam penelitian ini adalah metode deskriptif, yaitu metode yang menggunakan analisa peneliti dengan melihat peranan yang dilakukan oleh PPL terhadap petani dan catatan-catatan yang diperoleh dari pengamatan di lapangan melalui wawancara dengan petani atau responden.

Analisis data yang digunakan untuk menjawab tujuan kedua dalam penelitian ini tidak berbeda dengan analisis tujuan pertama yaitu metode deskriptif. Metode deskriptif tersebut menggunakan catatan-catatan hasil turun lapang yang diperoleh dari wawancara dengan petani atau responden. Data-data dan catatan-catatan tersebut diolah dan ditulis dalam bentuk narasi yang terstruktur dan terperinci dalam menggambarkan tingkat adopsi PTT petani padi sawah di Kecamatan Seputih Raman Kabupaten Lampung Tengah.

Analisis data yang digunakan untuk menjawab tujuan ketiga dalam penelitian ini adalah metode analisis statistik non parametrik korelasi Rank Spearman dengan SPSS 21 (Statistical Package for Sosial Science). Uji korelasi Rank Spearman digunakan untuk mencari hubungan antara peranan PPL dengan tingkat adopsi PTT petani padi sawah.

Analisis data yang digunakan untuk menjawab tujuan keempat adalah metode analisis statistik non parametrik korelasi Rank Spearman. Uji korelasi Rank Spearman digunakan untuk mencari hubungan antara tingkat adopsi PTT petani dengan Produktivitas padi sawah. 
Populasi penelitian ini adalah petani padi sawah yang terdapat di Kecamatan Seputih Raman berjumlah 99 orang responden dengan menggunakan perhitungan rumus Yamane (Ridwan dan Kuncoro, 2008). Sampel sebanyak 99 responden orang terbagi pada 14 Wilayah Kerja Penyuluh Pertanian (WKPP) dari 8 penyuluh dipilih secara Proposional Random Sampling. Penentuan sampel yang terbagi pada WKPP ditentukan menggunakan metode rumus (Nazir 1988), yaitu:

$$
\mathrm{na}=\frac{\mathrm{Na}}{\mathrm{N}} \times \mathrm{n}
$$

\section{Keterangan:}

na $=$ Jumlah petani di wilayah binaan

$\mathrm{n} \quad=$ Jumlah petani keseluruhan

$\mathrm{N}=$ Jumlah populasi keseluruhan

$\mathrm{Na}=$ Jumlah populasi di wilayah binaan

\section{HASIL DAN PEMBAHASAN}

\section{Peranan PPL dalam Adopsi PTT Petani Padi Sawah}

Peranan dilihat dari fungsi atau tugas sebagai PPL, yaitu dalam melakukan edukasi, diseminasi informasi, fasilitasi, konsultasi, supervisi, pemantauan, dan evaluasi (Mardikanto 1998). Peranan PPL dalam adopsi PTT petani padi sawah dibagi menjadi tiga kategori yaitu: rendah $(19,19-$ 26,36), sedang $(26,37-33,54)$, tinggi $(33,55-$ 40,70). Peranan PPL dalam adopsi PTT petani padi sawah di Kecamatan Seputih Raman berada pada klasifikasi sedang dengan interval rata-rata $(31,43)$. Secara rinci tingkat peranan PPL dapat dilihat pada Tabel 1.

Tabel 1. Sebaran responden berdasarkan tingkat peranan PPL di kecamatan Seputih Raman

\begin{tabular}{cccc}
\hline $\begin{array}{c}\text { Tingkat } \\
\text { peranan PPL } \\
\text { dalam adopsi }\end{array}$ & Klasifikasi & $\begin{array}{c}\text { Jumlah } \\
\text { responden } \\
\text { PTT (interval) }\end{array}$ & $\begin{array}{c}\text { Persentase } \\
(\%)\end{array}$ \\
\hline $19,19-26,36$ & Rendah & 14 & 14,14 \\
$26,37-33,54$ & Sedang & 54 & 54,54 \\
33,55-40,70 & Tinggi & 31 & 31,31 \\
\hline Jumlah & & 99 & 100 \\
Rata-rata & 31,43 (Sedang) & & \\
\hline
\end{tabular}

1. Peranan PPL dalam melakukan kegiatan edukasi

Peranan PPL dalam melakukan kegiatan edukasi termasuk dalam klasifikasi sedang dengan interval rata-rata 6,27. Edukasi yang diberikan PPL dinilai cukup baik dalam Frekuensi PPL melakukan sosialisasi tentang PTT padi sawah, memberikan arahan tentang PTT padi sawah, mengajarkan dan mendidik petani untuk memperoleh hasil yang maksimal melalui PTT padi sawah. Sejalan dengan penelitian Darmoko, Siata, dan Nurfathiyah (2014) dalam penelitian ini penyuluh sebagai pendidik terlihat dari kemampuan penyuluh pertanian lapangan dalam memberikan pengetahuan atau cara - cara dalam penerapan program percetakan sawah baru untuk mewujudkan ketahanan pangan dan kesejahteraan masyarakat

2. Peranan PPL dalam melakukan kegiatan diseminasi informasi

Peranan PPL dalam melakukan kegiatan diseminasi informasi termasuk dalam kategori sedang dengan interval rata-rata 4,19 yang artinya penilaian petani padi terhadap PPL dalam menyebarkan informasi tentang PTT padi sawah secara cukup baik atau jelas terkait pemecahan masalah yang dihadapi dalam PTT. Penyebaran informasi dan pemecahan masalah yang diberikan PPL dalam bentuk FGD (Forum Group Discussion) agar diperoleh hasil maksimal.

3. Peranan PPL dalam melakukan kegiatan fasilitasi

Peranan PPL sebagai fasilitator masuk dalam klasifikasi sedang dengan interval rata-rata 3,86. Peranan PPL dalam melakukan fasilitasi cukup membantu dan mendampingi terkait proses penerapan kegiatan PTT. Pendampingan PPL dalam melakukan fasilitasi dilihat berdasarkan apakah PPL membantu mendampingi petani dalam proses penerapan kegiatan PTT, apakah PPL memfasilitasi (baik berupa sarana maupun prasarana informasi) kepada petani dalam hal penerapan PTT.

4. Peranan PPL dalam melakukan kegiatan konsultasi

Peranan PPL sebagai konsultan atau penasihat sangat penting dalam kesuksesan penerapan PTT. Penilaian petani padi terhadap peranan PPL dalam melakukan kegiatan konsultasi dinilai 
sedang dengan interval rata-rata 3,57. Hal ini dikarenakan, peranan PPL dalam pertemuan dengan petani tidak terlalu sering sehingga petani terkadang kesulitan untuk meminta bantuan PPL dalam konsultasi kegiatan usahataninya.

5. Peranan PPL dalam melakukan kegiatan supervisi

Kegiatan supervisi dalam melakukan pengawasan terhadap usahatani padi salah satu indikator penilaian peranan PPL dalam melakukan kegiatan supervisi. Peranan PPL dalam kegiatan supervisi termasuk ke dalam klasifikasi sedang dengan rata-rata interval 3,58. Pengawasan yang dilakukan PPL masih biasa saja seperti musim tanam sebelumnya yaitu melakukan pengawasan hanya dengan kunjungan saja tidak melakukan pengawasan detail terkait pengawasan dalam pengendalian hama penyakit dan lain-lain.

6. Peranan PPL dalam melakukan kegiatan Pemantauan

Peranan PPL dalam melakukan pemantauanan yaitu kegiatan yang dilakukan oleh PPL menjalankan tugasnya sebagai pendidik selama kegiatan berlangsung, PPL melakukan pemantauan dan penilaian terhadap keaktifan petani menerapkan PTT, serta melakukan pemantauan terhadap kendala-kendala yang dihadapi petani pada saat penerapan PTT. Peranan PPL dalam melakukan pemantauan berada pada klasifikasi tinggi dengan interval rata-rata 4,34.

\section{Peranan PPL dalam melakukan kegiatan} evaluasi

Peranan PPL dalam kegiatan evaluasi, yaitu PPL mengevaluasi penyuluhan yang telah diberikan terkait PTT, indikator kesuksesan PPL mengevaluasi adalah: apakah PPL mampu mengukur sebelum (formatif), selama (on-going, pemantauan) dan setelah kegiatan PTT. Penilaian petani padi terhadap peranan PPL dalam melakukan evaluasi kegiatan PTT berada pada klasifikasi sedang dengan interval rata-rata 5,62. Menurut petani aktivitas PPL melakukan evaluasi kepada petani untuk memotivasi petani supaya tercapainya hasil yang lebih baik tidak begitu rutin dilakukan.
Tabel 2. Sebaran responden berdasarkan Tingkat adopsi PTT di Kecamatan Seputih Raman

\begin{tabular}{lccc}
\hline $\begin{array}{c}\text { Tingkat adopsi } \\
\text { PTT petani } \\
\text { padi sawah } \\
\text { (interval) }\end{array}$ & Klasifikasi & $\begin{array}{c}\text { Jumlah } \\
\text { responden } \\
\text { (orang) }\end{array}$ & $\begin{array}{c}\text { Persentase } \\
(\%)\end{array}$ \\
\hline $44,80-53,77$ & Rendah & 16 & 16,16 \\
$53,78-62,75$ & Sedang & 54 & 54,54 \\
$62,76-71,71$ & tinggi & 29 & 29,29 \\
\hline Jumlah & \multicolumn{3}{c}{59,41 (Sedang) } \\
Rata-rata & \multicolumn{3}{c}{100} \\
\hline
\end{tabular}

\section{Tingkat Adopsi PTT Petani Padi Sawah}

Adopsi adalah proses perubahan perilaku yang terjadi pada diri seseorang baik dalam bentuk perubahan sikap, pengetahuan, dan pola pikir setelah menerima pesan dari seseorang. Adopsi sebagai penerapan atau penggunaan sesuatu ide, alat-alat atau teknologi baru yang disampaikan berupa pesan komunikasi. Manifestasi dari bentuk adopsi ini dapat dilihat atau diamati berupa tingkah laku, metode, maupun peralatan dan teknologi yang dipergunakan dalam kegiatan komunikasinya Mardikanto dan Sutarni (1982). Tingkat adopsi PTT padi sawah dilihat dari penggunaan benih bermutu, pengairan, pemupukan, pengendalian HPT, serta penanganan panen dan pasca panen. Tingkat adopsi PTT petani padi dibagi menjadi tiga klasifikasi yaitu, rendah $(44,80-53,77)$, sedang (53,78-62,75), tinggi (62,76-71,71). Adopsi PTT petani padi sawah di kecamatan Seputih Raman berada pada klasifikasi sedang dengan rata-rata interval 59,41, hal ini menunjukkan bahwa petani di Kecamatan Seputih Raman sudah mengadopsi PPT dengan cukup baik. Tingkat adopsi dapat dilihat pada Tabel 2 .

\section{Produktivitas}

Produktivitas padi merupakan salah satu tujuan utama atau hasil akhir yang diinginkan. Berbagai cara termasuk memperbaiki fasilitas sarana dan prasaran, cara budidaya dan sebagainya telah dilakukan untuk meningkatkan produktivitas padi sawah. Hasil penelitian dan pengamatan produktivitas padi di Kecamatan Seputih Raman Kabupaten Lampung Tengah dapat dilihat pada Tabel 3. Tabel 3 menunjukkan bahwa rata-rata produktivitas padi di Kecamatan Seputih Raman adalah 5,90 ton/ha yang masuk dalam klasifikasi sedang. Hasil produktivitas petani padi sawah yang cukup baik dicapai melalui penerapanpenerapan PTT di Kecamatan Seputih Raman. 
Tabel 3. Produktivitas padi sawah di Kecamatan Seputih Raman Kabupaten Lampung Tengah

\begin{tabular}{cccc}
\hline $\begin{array}{c}\text { Produktivitas } \\
\text { (ton/ha) }\end{array}$ & Klasifikasi & $\begin{array}{c}\text { Jumlah } \\
\text { Responden } \\
\text { (Orang) }\end{array}$ & $\begin{array}{c}\text { Persentase } \\
(\%)\end{array}$ \\
\hline $4,48-5,23$ & Rendah & 5 & 5,05 \\
$5,24-5,99$ & Sedang & 42 & 42,42 \\
$6,00-6,72$ & Tinggi & 52 & 52,53 \\
\hline Jumlah & \multicolumn{3}{c}{5,90 (sedang) } \\
Rata-rata & 99 & 100 \\
\hline
\end{tabular}

\section{Hubungan Peranan PPL dengan Tingkat Adopsi PTT Petani Padi Sawah}

Hubungan antara variabel X (peranan PPL) dengan variabel Y (tingkat adopsi PTT petani padi sawah) dianalisis dengan menggunakan statistika non parametrik uji korelasi Rank Spearman dengan bantuan SPSS 21. Hasil pengujian hipotesis hubungan antara peranan PPL dengan adopsi PTT petani padi sawah di Kecamatan Seputih Raman Kabupaten Lampung Tengah, diperolehan hasil sig sebesar 0,016 dan $\alpha$ 0,1, sejalan dengan kaidah keputusan jika sig $0,016 \leq \alpha 0,1$ dapat disimpulkan bahwa Peranan PPL berhubungan nyata dengan adopsi PTT petani padi sawah di Kecamatan Seputih Raman Kabupaten Lampung Tengah.

Hasil ini sejalan dengan penelitian Aria, Hasanuddin dan Prayitno (2016), yang menyimpulkan bahwa tingkat peranan PPL terhadap keberhasilan program pengembangan Usaha Agribisnis Pedesaan sudah baik, dalam hal melakukan diseminasi informasi, fasilitasi, supervisi, pemantauan, dan evaluasi. Hasil penelitian ini sejalan dengan penelitian Sairi (2015) yang menyatakan penyuluh berperan dalam membantu pengembangan budidaya padi di Desa Sumber Sari Kecamatan Loa Kulu Kabupaten Kutai Kartanegara, yaitu penyuluh membantu dalam percepatan arus informasi, mendampingi masyarakat, menyediakan jasa sesuai dengan, masalah, memberi pertimbangan dalam pengambilan keputusan, penengah ketika bernegosiasi dengan pihak mitra/pihak lain dan memberikan motivasi dalam pengembangan usahatani. Hasil penelitian dari Ningsih, Effendi dan Sadar (2014), peranan PPL sebagai edukator dan pengawas berhubungan dengan penerapan SLPTT padi di Desa Tegal Yoso Kecamatan Purbolinggo Kabupaten Lampung Tengah.

\section{Hubungan Tingkat Adopsi PTT Petani dengan Produktivitas Padi Sawah}

Berdasarkan hasil pengujian hipotesis hubungan antara adopsi PTT petani dengan produktivitas padi sawah di Kecamatan Seputih Raman Kabupaten Lampung Tengah, dengan menggunakan uji statistik nonparametrik korelasi Rank Spearman. Adopsi PTT petani berhubungan nyata dengan produktivitas padi sawah di Kecamatan Seputih Raman Kabupaten Lampung Tengah. Perolehan hasil sig sebesar 0,080 dan $\alpha$ 0,1 , sejalan dengan kaidah keputusan jika sig 0,080 $\leq \alpha 0,1$ dapat disimpulkan bahwa adopsi PTT petani berhubungan nyata dengan tingkat produktivitas padi sawah di Kecamatan Seputih Raman Kabupaten Lampung Tengah.

\section{KESIMPULAN}

Peranan PPL dalam PTT petani padi sawah di Kecamatan Seputih Raman Kabupaten Lampung Tengah termasuk dalam klasifikasi sedang, artinya PPL cukup berperan dalam memberikan edukasi, diseminasi, fasilitasi, konsultasi, supervisi, pemantauan dan evaluasi, tingkat adopsi PTT padi sawah petani di kecamatan Seputih Raman termasuk dalam klasifikasi sedang, artinya adopsi PTT berdasarkan penggunaan benih bermutu, sistem tanam, pengairan, pemupukan, pengendalian HPT, penanganan panen hingga pasca panen sudah cukup baik, peranan PPL memiliki hubungan yang nyata dengan tingkat adopsi PTT petani di kecamatan Seputih Raman Kabupaten Lampung Tengah, tingkat adopsi PTT petani padi sawah memiliki hubungan yang nyata dengan produktivitas padi sawah di Kecamatan Seputih Raman Kabupaten Lampung Tengah.

\section{DAFTAR PUSTAKA}

Aria RA, Hasanuddin T, dan Prayitno RT. 2016. Peranan penyuluh pertanian lapangan (PPL) terhadap keberhasilan program pengembangan usaha agribisnis pedesaan (PUAP) di Kecamatan Sungkai Selatan Kabupaten Lampung Utara. JIIA. Universitas Lampung. Vol. 4 (4) : 430 - 436. http:// jurnal.fp.unila.ac.id/index.php/JIA/article/vie w/1526/1380. [20 November 2018].

Badan Pusat Statistik. 2016. Lampung Dalam Angka. Provinsi Lampung.

Darmoko, Siata R, dan Nurfathiyah P. Peranan penyuluh pertanian lapangan dalam penerapan program percetakan sawah baru di Kelurahan Simpang Kecamatan Berbak Kabupaten 
Tanjung Jabung Timur. Jurnal Sosio Ekonomika Bisnis. Vol.17 (2) : 43 -51. http://neliti.com/id/publications/43743. [20 Maret 2018].

Effendi I. 2005. Dasar-Dasar Penyuluhan Pertanian. Buku Ajar Penerbit Universitas Lampung. Bandar Lampung.

Mardikanto T. dan Sutarni S. 1982. Pengantar Penyuluhan Pertanian. Hapsara. Surakarta

Mardikanto T. 1998. Komunikasi Pembangunan. UNS Press. Surakarta.

Nazir M. 1988. Metode penelitian. Ghalia Indonesia. Jakarta.

Ningsih R, Effendi I, dan Sadar S. 2014 Peranan penyuluh dalam bimbingan teknologi SL-PTT (Sekolah Lapangan Pengelolaan Tanaman Terpadu) padi hibrida di Desa Tegal Yoso
Kecamatan Purbolinggo Kabupaten Lampung Tengah. JIIA. Vol. 2 (2) : 174-181. http:// jurnal.fp.unila.ac.id/index.php/jia/article/view /742/682. [20 November 2018].

Ridwan dan Kuncoro EA. 2008. Cara Menggunakan dan Memakai Analisis Jalur (Path Analysis). Alfabeta. Bandung

Sairi A. 2015. Peran petugas penyuluh pertanian dalam mengembangkan budidaya padi di Desa Sumber Sari Kecamatan Loa Kulu Kabupaten Kutai Kartanegara. E-Jurnal Ilmu Komunikasi. Vol. 3, No.2, Hal 150-164. http:// ejournal.unmul.ac.id/site/wp-content/up load. [20 Maret 2018].

Soetriono. 2006. Pengantar Ilmu Pertanian. Bayu Media. Malang. 